Resenha:

\title{
Nelson Mandela: Modesto Pleito a Madiba
}

\author{
Maria Manuela Araújo
}

«In my language there is a saying: 'Ndiwelimilambo enamagama'

('I have crossed famous rivers'). $»^{1}$

Nelson Mandela

Revisitar a autobiografia de Nelson Mandela, Long Walk To Freedom², afigura-se, no presente momento, um pertinente tributo à vida de Madiba. A recensão crítica em curso escolheu como linha orientadora de análise o ditado xhosa acima transcrito, citado e escolhido por Mandela como tema líder, organizador, da sua narrativa de vida.

A longa viagem discursiva do ditado xhosa, reinterpretado no texto autobiográfico de Nelson Mandela, tem como pontos de partida e chegada dois sistemas semióticos dissemelhantes, embora coexistentes, cruzando diferentes tempos e espaços. Da oralidade para a escrita, de tempos antigos para a modernidade, do campo para a cidade, a actualização moderna do ditado xhosa é um sintoma visível da «crioulização» ${ }^{3}$ entre literaturas oral e escrita, em benéfica convivência, mas em que esta última, menos sacralizada, ganha, no entanto, um tom público de contestação. Mandela, ao escrever o enunciado falado, ao fazê-lo falar noutra instituição linguística, redireccionando, na escrita, os ritmos e vectores semânticos da fala primeira, fez uma associação simbiótica que aponta para a «reoralização da literatura $»^{4}$, na cultura contemporânea de países onde a escrita caminha, a par e passo, com a oralidade.

Nelson Mandela recupera o ditado xhosa da irreversibilidade do tempo, fixando em código grafemático o que vive na sua memória e na memória de muitos dos seus leitores, introduzindo na sua realização escrita as variações que o seu cursus vivendi lhe propôs, ou seja, à luz do ditado xhosa o eu reordena a sua existência, à medida que organiza a escrita memorial da sua vida, liderada pelo conhecido motivo verbal. O tema estruturador do ditado xhosa é extrapolado dentro do plano de significação conotativo e reinventado por analogia com o seu sentido literal, que implica o esforço humano desenvolvido na luta que é a travessia de um rio, ou seja, a força e a coragem de quem ousa opor-se ao movimento transverso do seu caudal. No contexto linguístico em causa, o elemento natural rio

$1 \mathrm{O}$ texto em itálico é um ditado xhosa, citado e traduzido na autobiografia de Nelson Mandela. Cf. Mandela, 2002, vol. I, p. 121.

2 Mandela, 2002, vols. I e II. As citações seguintes desta obra serão indicadas logo após a citação, no corpo do texto, com a sigla M, I ou II, de acordo com o volume citado, seguida do número de página, entre parênteses.

3 O conceito reporta-se a Vítor Manuel de Aguiar e Silva. Ver Silva, 2002, p. 144.

4 Idem. 
pode simbolizar o fluido vital, individual e colectivo; atravessá-lo significa vencer uma etapa de vida, dar um passo em frente, não só em termos de conhecimento, mas também de libertação social e política.

O ditado xhosa que o texto de Mandela cita, descodifica e assimila, afigura-se plenamente investido da semântica frasal acima verbalizada, recriando a componente gnoseológica que lhe é intrínseca, mas introduzindo outra, uma nova vertente política: viver é, não só percorrer etapas de conhecimento, mas também conhecer para resistir à opressão do sistema ideológico vigente, e em cuja persistência de luta se consubstancia o percurso político opositor, ou seja, o Longo Caminho para a Liberdade. Desta forma, o eu autoral se estabelece como elo contemporâneo da antiga cadeia de transmissão oral, num gesto verbal inovador, ainda que de compromisso com a tradição oral, perpetuada no texto de forma criativa, mas sem quebra de coesão semântica, uma vez que a relação dialógica em causa assume contornos explícitos de imitação voluntária declarada. Por outro lado, as duas enunciações de eu estabelecem, entre si, uma relação simétrica de identificação, quer na sua forma de locução, quer a nível do seu conteúdo semântico, confluência discursiva que prova uma relação de identidade entre os espaços humanos que aqui se entrecruzam, pela partilha cultural de que os textos em causa se constituem testemunhos, embora o texto de Mandela comprove uma enorme transformação em si operada, movido pela sede de instrução, de mundivivência e de libertação dos povos oprimidos do seu país.

Nelson Mandela, por circunstâncias penalizadoras para o pai, chefe thembu acusado de insubordinação pelo magistrado local, é obrigado a abandonar a vila de Mvezo, terra natal localizada nas margens do rio Mbashe, e a fixar-se na vila de Qunu, ambas situadas no Transkei. Com a morte de seu pai, viu-se na contingência de deixar Qunu, levando consigo o que considerou ser a recordação dos dias mais felizes da sua vida. Assim, sofre na infância o primeiro abalo existencial, perdendo irrecuperavelmente o centro, o lar familiar: «[...] these three huts that I associated with all my happiness, with life itself, $[\ldots] \gg(\mathrm{M} \mathrm{I}, \mathrm{p} .21)$.

Em consequência, faz com a mãe a amargurada e silenciosa viagem a pé para Mqhekezweni, o Grande Lugar, capital de Thembuland, onde é confiado ao chefe thembu, Jongintaba Dalindyebo, que iria ser o seu guardião e benfeitor durante o período previsível de dez anos. À chegada, embora experimente uma sensação momentânea de deslumbramento com a riqueza e a ordem da Grande Casa do regente, quando vê Jongintaba e o seu tribunal, composto por vinte anciãos tribais à frente da casa principal, é invadido, novamente, por um sentimento de desenraizamento e impotência, perante o destino que a situação familiar lhe impunha: «In that moment of beholding Jongintaba and his court I felt like a sapling pulled root and branch from the earth and flung into the centre of a stream whose strong current I could not resist.» (M I, p. 23). Apesar de ter frequentado a escola anteriormente, é em Mqhekezweni que os grandes tradicionalistas lhe ensinam a verdadeira história africana, contada oralmente por reconhecidas figuras que vinham de longe resolver disputas e julgar processos, como o Chefe Joyi (M I, pp. 32, 33) que, apesar de muito velho, era exímio na arte da pantomima, com a qual fazia acompanhar o desenrolar das suas histórias.

Embora Mandela, em Mqhekezweni, tivesse vivido, antecipadamente, a sensação ingénua de rapaz que vem da aldeia para a grande cidade, por esta se afigurar, a seus olhos, mais sofisticada do que Qunu, o certo é que ele ainda não tinha atravessado o primeiro "rio famoso" da sua vida: «I had never crossed that river, and I knew little or nothing of the world beyond it, a world that beckoned me that day.» (M I, p. 43). Mandela refere-se ao rio 
Mbashe, que adquiriu um valor excepcional para si, porque fazia parte do cenário iniciático onde tinha decorrido o rito de puberdade da sua geração. O rio Mbashe é considerado o primeiro rio importante da sua vida, porque nele se purificou antes da corajosa cerimónia da circuncisão, desenrolada nas suas margens. O rio onde o neófito, segundo a tradição, acede a um tempo sagrado primordial, purificador, simboliza para si o testemunho do encantador mundo perdido da infância e da adolescência, dizendo pelas suas palavras «[...] the world of sweet and irresponsible days at Qunu and Mqhekezweni.» (M I, p. 44). A travessia do rio Mbashe equivale ao primeiro passo simbólico em direcção à modernidade. $\mathrm{O}$ destino que Jongintaba lhe reservava era ser conselheiro de Sabata e, para tal, era necessário receber instrução. Por essa razão, Mandela abandona o lar que o adoptou, atravessa o rio Mbashe e entra, como aluno interno, no Instituto Clarkebury, simultaneamente Escola Secundária, Escola de Formação de Professores e Técnico-Profissional, com a particularidade de o seu reitor, o Reverendo Harris, ser considerado pelo seu regente como «[...] a white Thembu» (M I, p. 46), assim como ensinar os futuros governantes a ser cristãos, e governantes tradicionais (M I, p. 46).

Clarkebury, sentido como um espaço mais grandioso do que Mqhekezweni, foi o primeiro sítio ocidental onde Mandela viveu, o primeiro novo mundo não africano, com regras desconhecidas e onde a sua ilustre ascendência de Ngubengcuka foi inteiramente ignorada, pelo que rapidamente compreendeu que o seu caminho tinha de ser trilhado com base nas suas qualidades individuais, e não na sua linhagem. Considera-se, assim, inaugurado o longo percurso que vai culminar em Joanesburgo, o centro cosmopolita onde cresceu o projecto nacionalista sul-africano, o mundo dos ideais e debates políticos clandestinos, iniciados em Witwatersrand, a grande cidade moderna que viu nascer «a Freedom Fighter $»^{5}$, o qual foi ascendendo sem nunca abdicar das suas raízes culturais, defendidas, mas redefinidas no decurso dos vários contextos políticos que vai atravessando.

Da tradição para a modernidade, do saber ancestral para as aprendizagens, vivencial, académica e política do hostil mundo do progresso, a figura emblemática de Mandela personifica a modernidade africana, um outro modelo de civilização, contestatário da própria tradição africana, embora culturalmente inclusivo, mas não alienado pelo Ocidente, porque foi mantendo vivo o diálogo com as matrizes identitárias africanas, as quais sempre dignificou, e das quais revela orgulhar-se.

O eu autobiográfico em causa, no acto rememorativo da escrita que reconstitui o seu regresso de Joanesburgo a Mqhekezweni, por ocasião da morte do seu regente, alude às contrariedades passadas entre ambos, motivadas pela desobediência à tradição, mencionando o tempo de retrospecção e redescoberta que viveu por essa altura. O regresso ao "Grande Lugar" desperta em si uma longa reflexão existencial, em que se auto-avalia e reequaciona o sentido da sua vida, colocando em evidência o valor de um passado que considera adverso, e no qual distingue duas etapas, aludindo a um futuro igualmente indiciador de várias fases atribuladas: «I had, since 1934, crossed many important rivers in my own land: the Mbashe and the Great Kei, on my way to Healdtown; and the Orange and the Vaal, on my way to Johannesburg. But I had many rivers yet to cross. » (M I, pp. 121, 122).

Assim, o sujeito de enunciação estabelece o ano de 1934 como marco cronológico de relevo, início de mudança, afastamento do seu mundo primeiro, da infância, em que pensar e falar o cosmos na língua-mãe xhosa se constituiu como princípio edificador de si e do universo envolvente, equilíbrio inicial gerido por uma ordem sagrada, díspar da ordem racional ocidental, que escolheu conhecer.

5 Alusivo ao título da Parte Três, «Birth of a Freedom Fighter». Cf. Mandela, 2002, vol. I, p. 133. 
A primeira etapa do seu percurso, iniciado em 1934, corresponde ao começo de um processo de integração do eu no mundo da modernidade ocidental, construído em contexto colonialista. A aprendizagem da literacia, principal instrumento de afirmação social, move o sujeito em direcção à escola. Nelson Mandela deixa o mundo tradicional rural onde tinha nascido e, após os rituais de circuncisão, dispõe-se a atravessar o rio Mbashe, em 1934, em direcção ao Colégio Interno de Clarkebury, localizado numa missão metodista, conhecida como a instituição de ensino mais avançada para os africanos negros de Thembuland.

Em 1937, Mandela, com dezanove anos, para chegar a Healdtown, atravessa o rio Grand Kei e entra no Colégio Wesleyan, em Fort Beaufort, onde, pelas suas palavras, lhes era criada a aspiração a serem «black Englishmen» (M I, p. 53). Contudo, a forma como relata a visita do poeta xhosa Krune Mqhavi à escola e o incidente simbólico da zagaia que bate no suporte do cortinado mostram uma consciência contrária à intenção do colégio, ao despertar no seu imaginário algo que considerou muito importante: « the clash between the culture of Africa and that of Europe. » (M I, p. 59).

Nelson Mandela continua a sua formação académica no Colégio Universitário de Fort Hare que, fundado em 1916, é considerado, até 1960, o único centro de ensino superior para negros na África do Sul. Revivendo o mérito de duas figuras proeminentes que o impressionaram, o professor Z.K.Matthews e o professor Jabavu, Mandela refere Fort Hare do seguinte modo: «Fort Hare was both home and incubator of some of the greatest African scholars the continent has ever known.» (M I, p. 64). Neste passo textual, menciona o facto de o professor Z.K. Matthews ter sido influenciado pela autobiografia de Booker T. Washington, Up from Slavery, acção que merece ser destacada, por apontar para a influência que os líderes afro-americanos exerceram nos meios intelectuais africanos de orientação nacionalista. Do professor Jabavu, Mandela recorda os seus conhecimentos enciclopédicos, tanto na área da cultura europeia, como, especialmente, na área da cultura xhosa, tendo sido o presidente-fundador da Convenção Pan-africana, em 1936 (Cf. M I, p. 64).

Mandela, no segundo conturbado momento de vida, entra em conflito com dois sistemas convencionais que se opõem, mas que, de forma igual, sujeitam o indivíduo à sua cega obediência: em colisão com o mundo determinado pelo modelo civilizacional da modernidade ocidenal, mas também em antagonismo com o sistema tradicional regulador da sua cultura de berço, particularmente com a escolha de uma possível noiva, por parte do seu tutor, dentro da sua cultura de origem, mas à qual era totalmente alheio.

Assim, em Fort Hare, Mandela demite-se do Conselho Representativo dos Estudantes, o que correspondeu a uma diplomática expulsão do colégio. Em consequência, regressa a Mqhekezweni onde, de acordo com os princípios da sociedade tradicional xhosa, o seu regente lhe tinha escolhido uma noiva, a filha do padre thembu local. Mandela não consente, tendo este gesto de transgressão acentuado o seu drama de vida, pelo que se vê obrigado a fugir para Joanesburgo.

A caminho de Joanesburgo, atravessa então os rios Orange e Vaal, cursos hídricos que simbolicamente se constituem como obstáculos a quem se dirige, em fuga e à deriva, para o Norte. Joanesburgo corresponde a uma terceira longa etapa de vida, marcada por uma árdua luta de sobrevivência humana e ideológica. Nelson Mandela começa por trabalhar em Crown Mines, como guarda-nocturno. Em 1942, conclui a sua licenciatura, e em 1943 inscreve-se na Universidade de Witwatersrand, para fazer a parte académica necessária ao exercício do seu curso de Direito, tomando um contacto mais assíduo e profundo com a intelectualidade política, que o levou a aderir ao ANC.

O êxodo em busca da modernidade, ao abrir-lhe novos horizontes, cria-lhe, paralelamente, uma maior consciência do grau de dificuldade a ultrapassar para atingir os 
objectivos a que se tinha proposto, estado de amadurecimento que o leva a proferir, em Mqhekezweni, o ditado xhosa epigrafado, sobre o qual se disserta.

Deste modo, é a consciência política ganha em plena maturidade, em Joanesburgo, que explica o sentido da frase: «I had many rivers yet to cross. » (M I, p.122). Mandela mostra aperceber-se de que o percurso iniciado dentro do ANC, com as duas formas de luta planeadas, a fase da resistência passiva (de 1912 a 1952/3) e a fase da violência, a partir de 1953, iriam, de certeza, valer-lhe perseguições políticas várias, que haviam, mais tarde, de resultar em vinte e sete anos de prisão, dezoito dos quais no maior de todos os cárceres, Robben Island.

A sua cela foi visitada pelo, então, senador Barack Obama, que quis ter a experiência de espreitar pelo postigo celular de Mandela: dois olhos já livres, que levaram o reconhecimento de Frederick Douglass, mesmo de Booker T. Washington, de W.E.B. Du Bois, mesmo de Garvey, do grande Martin Luther King e de muitos outros, africanos e afro-americanos, os quais abriram e trilharam, nas matas, do Sul e do Norte, a bordo do underground railroad, caminhos para a liberdade, sempre sem atalhos, e por essa razão, foram e continuam a ser, difíceis e longos.

\section{Referências}

ARAÚJO, Maria Manuela. (2010). Diálogos Literários entre a África e os E.U.A. no Despertar dos Nacionalismos Africanos. Lisboa: Edições Colibri.

MANDELA, Nelson. (2002). Long Walk to Freedom, vols. I e II. (1994). Great Britain: Abacus. SILVA, Vítor Manuel de Aguiar e. (2002). Teoria da Literatura. Coimbra: Livraria Almedina. 